


\title{
POÉTICA DE LO SINIESTRO EN EL RELATO "EL PERJURIO DE LA NIEVE” DE ADOLFO BIOY CASARES
}

\author{
POETICS OF THE SINISTER IN THE STORY 'THE PERJURY OF \\ THE SNOW" BY ADOLFO BIOY CASARES
}

José Miguel Rodríguez Zamora

\begin{abstract}
RESUMEN
Este artículo analiza "El perjurio de la nieve" (1944) del escritor argentino Adolfo Bioy Casares como una propuesta de metaliteratura. Para sustentar este postulado, en primer lugar, se determina la semántica de lo siniestro (Das Unheimlich) en la literatura como presupuesto del análisis literario del relato. Posteriormente, se examina la estrategia literaria según la cual el tiempo, el espacio y los personajes construyen una doble dimensión narrativa propia de la segmentación argumental. Asimismo, se explora el topos literario del doble (Doppelgänger) como la fragmentación complementaria de los caracteres y la sutil descomposición del acto narrativo en una epistemología que pretende superar la dualidad sujeto-objeto. Se concluye que, en la contraposición de dos construcciones poéticas ambiguamente creadas por el falso testimonio del narrador, se oculta la pertinaz impostura de la realidad.

Palabras clave: Bioy Casares; literatura fantástica; metaliteratura; lo siniestro; el doble.
\end{abstract}

\begin{abstract}
This article analyzes "El perjurio de la nieve" (1944) of the Argentine writer Adolfo Bioy Casares as a proposal of metaliterature. To support this postulate, first of all, it is determined the semantics of the sinister (Das Unheimlich) in the literature as a presupposition of the literary analysis of the story. Subsequently, it is discussed the literary strategy according to which time, space and the characters construct a double narrative dimension of argumentative segmentation. It also explores the literary topos of the double (Doppelgänger) as the further fragmentation of the characters and subtle decomposition of the narrative act into an epistemology that seeks to overcome the subjectobject duality. It is concluded that, in contrast, two poetic constructions ambiguously created by the false testimony of the Narrator, hides the persistent imposture of the reality.

Key words: Bioy Casares; fantastisc literature; metaliterature; sinister; double.
\end{abstract}

"No creo que la única interpretación de estos hechos sea la mía. Creo, simplemente, que es la única verdadera" Adolfo Bioy Casares (2008, p. 171)

Dr. José Miguel Rodríguez Zamora. Profesor jubilado, Universidad de Costa Rica. Costa Rica. Correo electrónico: jomiroz@gmail.com

Recepción: 19- 10- 17

Aceptación: 17- 11- 17 


\section{Introducción}

Tiempo, imaginación, memoria y, al fin, muerte. En el cuento "El perjurio de la nieve" (1944) el lector recorre el relato en busca de una realidad definitiva, conocida y lineal. Pero este le niega un asidero. A cambio, lo introduce en un laberinto complejo y sutil de inversiones de fechas y de espacios, de máscaras y de espejos. Si la realidad es un lenguaje efímero, inasible, entonces pequeñas hojas, como una suerte de indeterminación, se borran en un elusivo calendario. Es la insustancial presencia de los seres, las cosas y los acontecimientos. Acontecimientos es una palabra importante en este paraje narrativo, pues, a la manera de la fantasía metafísica, remite a la ambigua condición de la existencia. O, dicho de otro modo, a situaciones superpuestas sin solución de continuidad. Tal sinuosidad no es en modo alguno un caos; todo lo contrario, es un universo en el cual se desenfoca lo esperado, donde la realidad, cual mítico plan de evasión, es un irrevocable destino colectivo.

Se suele discutir si este texto es un relato policíaco, sobrenatural o fantástico. Las barreras se difuminan y el lector perplejo se precipita en la extrañeza sin advertirlo. Como en toda hábil conspiración, los hechos evidentes y obvios señalan un camino ambiguo. La trivialidad es invadida por el enigma y la familiaridad da paso al desconcierto. En esta construcción metafísica el tiempo y el espacio se desplazan discontinuamente, los personajes intercambian papeles y el amor se descompone en una maraña de contradicciones y equívocos. La activa presencia masculina contrasta con la elusiva, evanescente y fantasmal presencia -casi ausencia- de los personajes femeninos. La casa cerrada es una excusa para otras alternativas en una ilusión de encuentros y desencuentros aparentemente fortuitos pero sellados por la fatalidad. Los relatos superpuestos remiten a una idea frecuente en la literatura: la memoria es lo que nos preserva de caer en la nada.

Para el estudio de este cuento se comienza por hacer una revisión de los conceptos de metaliteratura y de literatura fantástica, sus características y sus elementos literarios, particularmente la idea de la ruptura o quiebra con la realidad. Es decir, la contraposición de dos realidades, la extraliteraria y la intraliteraria. Como es sabido, en el lugar de este conflicto surge lo siniestro y lo ominoso. La reflexión inicial ofrece importantes elementos teóricos para comprender el relato. A continuación, se analiza la estructura argumental. En este caso se estudian los diversos planos narrativos, el tiempo, el espacio y sus consecuencias literarias. Por último, se examinan las contraposiciones y las imágenes especulares; en particular los dos elementos que Bioy Casares toma del topos del doble: la fragmentación complementaria de los caracteres y la sutil descomposición del acto narrativo en una epistemología que pretende superar la dualidad sujeto-objeto. Se finaliza con una reflexión inconclusa sobre las incoherencias sumergidas en los intersticios de la realidad.

\section{Metaliteratura y poética de lo siniestro}

Se puede conceder que "El perjurio de la nieve" es -entre muchas cosas- un relato de metaliteratura y de teoría de la creación literaria. Ciertamente, la construcción de este cuento, la caracterización de los personajes, la ubicación espacio-temporal, la trama argumental, así como la elección lingüística, plantean el tema de la literatura dentro de la literatura. Esto es importante: no se trata de una reflexión sobre la literatura desde arriba, sino, más bien, desde el interior de la creación literaria. El autor construye una idea de la literatura con los elementos 
propios de este complejo relato. En el inolvidable "Prólogo" a la famosa Antología de la literatura fantástica, compuesta por el mismo Bioy Casares en conjunto con Silvina Ocampo y Jorge Luis Borges, ha señalado que el cuento fantástico posee leyes propias:

No debe confundirse la posibilidad de un código general y permanente, con la posibilidad de leyes. [...] Pedimos leyes para el cuento fantástico: pero ya veremos que no hay un tipo, sino muchos, de cuentos fantásticos. Habrá que indagar las leyes generales para cada tipo de cuento y las leyes especiales para cada cuento. El escritor deberá, pues, considerar su trabajo como un problema que puede resolverse, en parte, por las leyes generales y preestablecidas, y, en parte, por leyes especiales que él debe descubrir y acatar (Bioy Casares, 1997, p. 6)

El destino del relato fantástico consiste en que el lector debe aceptar las reglas impuestas por el autor. O, más precisamente, tanto el autor como el lector -en tácito pactose supeditan a las normas exigidas por el propio relato. Asimismo, como en toda buena obra literaria, en esta narración se encuentra un método, un modelo narrativo, un sistema de normas y de ideas estéticas generales. El relato estipula la condescendencia con la palabra, un modo de exponer los acontecimientos y de generar la ilusión de la otredad. Es, en consecuencia, una forma de hacer la literatura, un por qué literario, en suma, una verdadera poética. La estructura macrotextual evidencia una ruptura con la realidad para establecer, en su lugar, una poética literaria de lo fantástico. Y con ello el autor termina por romper los moldes de la literalidad convenciona (García Berrio, 1994, p. 250).

También las fronteras están cambiando continuamente. No es solo la idea del lugar como entorno rígido y ordenado, más bien es un espacio móvil y dúctil. Gradualmente los límites se vuelven más imprecisos. La estética de lo fantástico lleva esta ruptura de límites a una extrema tensión. Si no existe ninguna literatura que sea mimética, copia fiel de la realidad, esfuerzo perseguido en vano por el realismo y el naturalismo, aun menos en la literatura fantástica. Porque, como ha señalado el famoso teórico Gerard Genette, en el discurso narrativo se ha operado una metamorfosis cuyo origen se encuentra en la aparición de la modernidad y que responde a una construcción del sujeto moderno como persona con características psíquicas particulares y un entorno histórico diverso en el cual, siguiendo a Ann Banfield, "El relato es la forma literaria que exhibe la propia estructura del pensamiento moderno" (Genette, 1998, p. 69). Una virtualidad que designa la transposición de la estructura arquitectónica en teoría estética.

La literatura fantástica consiste, más que en la delimitación de un género, en la conceptualización de una estética y, en consecuencia, de un recurso para afrontar una forma literaria de límites imprecisos, ciertamente, pero con características propias, y con ello construir una realidad artística. O, mejor dicho, de infinitas realidades imposibles. La asincronicidad y la sobreexposición -frecuentes en este tipo de literatura- contribuyen a poner en evidencia la vulnerabilidad de lo aceptado. Dentro de la estética literaria la subversión de la realidad le confiere esta condición de fantástico. Si el vértigo de lo real se niega a ser apresado aún en la fotografía del reportero gráfico, menos será en la tenue prisión de las palabras. El famoso crítico y teórico de la literatura Terry Eagleton lo ha resumido con las siguientes palabras:

[...] las formas y técnicas de la ficción son autónomas en relación con la realidad en el sentido de que, si no mantuviera cierta distancia con respecto a ella, no podría esculpir sus materiales de formas tan distintas. La ficción da testimonio del hecho de que el mundo no nos obliga a representarlo de un único modo, lo cual no quiere decir que podamos representarlo de algún modo anticuado (2013, p. 214) 
Ciertamente, esta acertada afirmación adquiere mayor relevancia en la literatura fantástica. La misma se sustenta del elemento de la ruptura, de la duda, la incertidumbre en diversos niveles de "experiencias disidentes" (Nandorfy, 2001, p. 258). La sensación de presencia permite al lector ese momento de duda e incertidumbre creando un estado mental con la irrupción de lo otro, lo intruso, lo diferente, lo siniestro. Es una "realidad enriquecida por la diferencia" (Nandorfy, 2001, p. 259).

En esta misma línea se encuentra una interesante propuesta de David Roas que en parte coincide con la apreciación del famoso escritor y crítico polaco Stanislaw Lem (1974, passim). Roas comienza con una definición de la literatura fantástica, a saber: "Un discurso en relación intertextual constante con ese otro discurso que es la realidad, entendida siempre como una construcción cultural" (2011, p. 9).

$\mathrm{Su}$ propuesta incluye cuatro elementos esenciales, a saber: la confrontación con la realidad, la construcción de lo imposible, el efecto del miedo y, por último, un uso particular del lenguaje. En consecuencia, existe una confrontación de dos factores, uno extratextual caracterizado como la realidad racional con límites muy fijos, frente a otro, una construcción intratextual que transgrede los límites de la realidad (Roas, 2011, p. 30). Este es el lugar en el cual irrumpe la imaginación y la fantasía, e, incluso, la ironía. Y el cuento "El perjurio de la nieve" no está exento de la ironía. Lo increíble e inverosímil suponen una ruptura que genera en el receptor un efecto de miedo, extrañeza e inquietud. Es el territorio privilegiado de lo siniestro y lo ominoso. Pero, ¿en verdad estas realidades son tan diferentes?

Por supuesto, para el imaginario de occidente las expresiones relatividad, indeterminación, teoría del caos, multiversos, dimensiones múltiples, figuras fractales, redes neuronales, neuroplasticidad, efecto mariposa, ya son de uso corriente. Con ellas se expresa una concepción de la realidad que rompe con los modelos rígidos de la ciencia y de la metafísica de siglos anteriores. La irrupción de este nuevo paradigma supone pluralidad de modelos explicativos y la puesta en evidencia de la inconsistencia de las cosmovisiones del pasado. Y, de nuevo, ha vuelto a resurgir la antigua pregunta filosófica, ¿qué es la realidad? Sobre este tema, y en relación con la literatura, David Roas señala que el desarrollo de las ciencias físicas, particularmente de la teoría de la relatividad y de la física cuántica y de sus exitosos resultados experimentales, así como de los actuales avances de las neurociencias han abierto las posibilidades hacia fronteras antes impensadas (Hawking, 2011, pp. 13-16). ¿Cuáles son los límites de la realidad? Si en el pasado el lector había dejado de ser ingenuo frente a la sociedad, la política, la religión y la psicología, ahora lo es confrontado con el conocimiento, el tiempo y el espacio, es decir, frente a la absoluta realidad (Ruiz-Lapuente, 2011, pp. 91-96).

En consecuencia, la literatura, al igual que la realidad, es un discurso construido tanto mental como socialmente. La objetividad se construye colectivamente. La obra literaria, se atiene a su propia ficcionalidad y se proyecta hacia el mundo extratextual. Siguiendo el concepto de coeficiente de irrealidad, propuesto por Rachel Bouvet, Roas problematiza la visión convencional al exponer la fragilidad de los conceptos compartidos y la arbitrariedad del discurso de realidad que, además, se impone por la fuerza de la ideología y del poder. Es una poética en la cual, "La representación o, mejor dicho, el intento de representación de dicho fenómeno supone la crisis de esa ilusión de lo real" (Roas, 2011, p. 129).

Es interesante anotar un elemento esencial para "El perjurio de la nieve". Al alejarse de lo familiar y de lo convencional, la realidad se resquebraja; y, como se verá más adelante, incluso el "yo" único, ilusión del sujeto, se rompe en muchos fragmentos: el doble, la desmemoria, lo irreconocible, etc. (Roas, 2011, p. 84). Lo reafirma al decir lo siguiente: 
Mi objetivo es demostrar que el miedo es una condición necesaria para la creación de lo fantástico, porque es su efecto fundamental, producto de esa transgresión de nuestra idea de lo real sobre la que vengo insistiendo. Por eso todo relato fantástico -contradiciendo a Todorov- provoca la inquietud del receptor (Roas, 2011, p. 88)

Por otra parte, es sugestivo observar que la literatura fantástica, a pesar de poseer todas las características de la gran literatura canonizada por la crítica, ha sido objeto de exclusión, posiblemente debido a su carga de subversión ideológica. Es una literatura que posee un fuerte peso de crítica social y de denuncia de las convenciones establecidas por la cultura y por la sociedad capitalista industrial. Es lo que Rosemary Jackson apropiadamente llama escepticismo civilizador (2001). Para explicarlo afirma lo siguiente: "La expulsión de lo fantástico a los márgenes de la cultura literaria es en sí mismo un gesto ideológico significativo, no muy distinto del silenciamiento de lo irracional por parte de la cultura" (Jackson, 2001, p. 143).

Sobre esta particular conviene precisar la propuesta de Tzvetan Todorov ya mencionada. Basado casi exclusivamente en el estudio de la literatura fantástica europea del siglo XIX, asevera que la relación que existe entre la realidad, cualquiera que sea la definición de la misma, y la construcción de lo fantástico reside en la "vacilación que experimenta un ser que solo conoce las leyes naturales, ante un acontecimiento al parecer sobrenatural" (Todorov, 2006, p. 24). Y, agrega, tres características esenciales, a saber:

En primer lugar, es necesario que el texto obligue al lector a considerar el mundo de los personajes como un mundo
de personas vivientes, y a vacilar entre una explicación natural y una explicación sobrenatural de los acontecimientos
evocados. Luego, esta vacilación puede ser sentida también por un personaje; de ese modo el papel del lector es,
por así decirlo, confiado a un personaje y al mismo tiempo la vacilación se encuentra representada, se convierte
en uno de los temas de la obra; en el caso de una lectura ingenua, el lector real se identifica con el personaje. Por
último, importa que el lector adopte cierta actitud ante el texto: negará tanto la interpretación alegórica como la
interpretación "poética". Estas tres exigencias no tienen un valor semejante. La primera y la tercera constituyen
verdaderamente el género; la segunda puede no ser cumplida (2006, pp. 32-33)

De este modo, el autor puede establecer una estipulación sintáctica y semántica de la obra fantástica dentro de la designación de posibles rupturas con la realidad. Surge, entonces, una indeterminación o una ambivalencia entre la realidad aceptada de acuerdo con las leyes cotidianas y la quiebra de las mismas por parte de un acontecimiento insólito, pero a condición de una invitación de verosimilitud.

Pero conviene seguir adelante y profundizar en los efectos que el relato tiene para el lector real. Uno de ellos, el más importante, es el de lo siniestro y ominoso. En 1919 Sigmund Freud publicó su famoso ensayo Lo siniestro (Unheimlich). El autor apunta desde el primer párrafo la intención de enfrentarse desde un abordaje estético-psicoanalítico, ejemplificado sobre todo por dos textos magistrales de E.T.A. Hoffmann, Los elíxires del diablo y, en particular, "El hombre de la arena" que presentan una completa expresión de la literatura fantástica europea del siglo XIX. También nos advierte desde el inicio que este término, lo siniestro u ominoso, "está próximo a lo de lo espantable, angustiante, espeluznante..." (Freud, 1981, p. 2 483). En consecuencia, lo siniestro abarca un movimiento, una especie de dialéctica que oscila entre dos polos irreconciliables. Por un lado, está lo conocido, lo familiar, lo seguro y confortable. Pero, por otro lado, se encuentra lo desconocido, lo poco familiar que es también lo atemorizante, lo escondido, peligroso y amenazante. Y, en medio de ambos, la irrupción de lo novedoso. Cuando se enfrentan estos elementos originan los sentimientos de desazón, intranquilidad e incluso, de miedo. La ruptura del límite, del paso del umbral, remite a lo desconocido donde acechan las fuerzas instintivas. La manifestación de lo reprimido, de 
lo oculto del inconsciente, saca al lector de la zona de confort y lo proyecta a un mundo de incierta ontología. En efecto, la literatura fantástica conlleva, implícita o explícitamente, el factor ominoso como parte de sus características esenciales.

Pero esto aún no es concluyente. Otro especialista en literatura fantástica, Víctor Bravo, le hace una acertada crítica tanto a Freud como a Todorov al afirmar que ambos, a su modo, han simplificado el efecto de la literatura fantástica. En realidad, afirma Bravo, el psicoanálisis desplazó el estudio literario hacia el ámbito de los protocolos clínicos, pero de ninguna manera sustituyó a la literatura fantástica. La literatura fantástica funciona "como una puerta emergente de ese espacio de clausura que es el horror" (Bravo, 1988, p. 43).

Expresión que le calza muy bien a "El perjurio de la nieve" porque es una forma de expresar un pertinaz ciclo de lo siniestro en el ámbito de un cuento policial de cuyo destino, como un eterno retorno, es imposible escapar. Bioy Casares desenvuelve formas estilísticas para mantener la estructura argumental de lo fantástico a lo largo de la misma. En esta obra, el espacio y el tiempo, la desvanecida atmósfera, la confusión de personajes y el juego de tiempos lingüísticos arrastran al lector hacia lo siniestro, lo ominoso.

Cuando al final el lector es confrontado con las posibles explicaciones, ambos mundos, el narrativo y el extranarrativo, se han superpuesto de forma tal que impiden una separación tajante. Con ello, Bioy Casares plantea una cuestión esencial de la literatura, la de la construcción de la verosimilitud literaria y del alcance estético de la narración. Asimismo, al leer este cuento, el lector sabe que se está refiriendo a otras obras literarias, no solo cómo intertextos, sino, más bien como un camino hacia la construcción de una teoría de la literatura en sí misma; como un discurso que dialoga recursivamente consigo mismo (Martínez Fernández, 2001, p. 51). Es, en consecuencia, una metaficción de textualidad alusiva a una apertura semiológica.

\section{Estructura narrativa}

"La realidad (como las grandes ciudades) se ha extendido y se ha ramificado en los últimos años. Esto ha influido en el Tiempo; el pasado se aleja con inexorable rapidez" (Bioy Casares, 2008, p. 140). Con estas palabras lapidarias se inicia la narración. Este incipit pone en guardia al lector: el espacio y el tiempo van a configurar una extraña realidad. Tiempo con mayúscula, así lo ha querido el autor para señalar -según parece- una dimensión que excede el tiempo fortuito de los acontecimientos cotidianos. Tiempo como una fatalidad que determina los hechos, los personajes y las incertidumbres. En este juego se entremezclan continuamente la presencia del autor y del narrador, ello proporciona una enmarañada superposición entre el tiempo objetivo y el tiempo de la memoria; entre lo verdadero y lo verosímil, lo virtual y lo real.

Ciertamente, la naturaleza polifónica de este relato está compuesta por una compleja multiplicidad de voces que ayudan a articular la historia. Sinfonía de superposiciones asincrónicas donde la técnica narrativa lleva al lector a una situación límite en la cual varios personajes enfrentan el enigma y muestran sus posibles soluciones. Considerada dentro del género policial, presenta, a la manera de Rashomon, del Cuarteto de Alejandría de Durrell, Mientras agonizo de Faulkner o aún de los cuatro Evangelios, una misma historia contada desde ópticas distintas. Ellas ofrecen pistas para configurar el relato, su resolución o la imposibilidad de llegar a un final concluyente. Este procedimiento, por lo demás, coincide con su utilización en la historia literaria dentro de la épica como una fascinación de la interpretación (Moretti, 1996, pp. 11-34). Es una compleja estratificación de lapsos narrativos con un encadenamiento 
analéptico basado en el prólogo, el informe, y el recuerdo. Frente el misterio del cuarto cerrado Bioy Casares rechaza una explicación racional y lineal a manera de los relatos policíacos. En su lugar opta por la superposición de relatos y la especularidad de los personajes. Con ello consigue un fuerte efecto psicológico en el lector. A esta narración se puede aplicar -casi literalmente- lo que Borges ha señalado en su "Prólogo" a La invención de Morel:

\begin{abstract}
Las ficciones de índole policial -otro género típico de este siglo que no puede inventar argumentos- refieren hechos misteriosos que luego justifican e ilustran con hechos razonables; Adolfo Bioy Casares, en estas páginas resuelve con felicidad un problema acaso más difícil. Despliega una Odisea de prodigios que no parecen admitir otra clave que la alucinación o que el símbolo, y plenamente los descifra mediante un solo postulado fantástico pero no sobrenatural. [...] He discutido con su autor los pormenores de su trama; la he releído: no me parece una imprecisión o una hipérbole calificarla de perfecta (2007, p. 31)
\end{abstract}

Los intertextos de citas y autores, frecuentes en el cuento, (Meyrink, De Quincey, Rubén Darío, Jean Paul, Schopenhauer, Calvino, Coleridge, Shelling, Shelley, Keats), contribuyen a establecer esta compleja poética del decir literario. Pues la literatura existe como el intento siempre en lucha por reconstruir la realidad en su ilimitada profusión y, a la vez, la trágica constatación de la imposibilidad de la recuperación de la elusiva realidad. No se puede liberar a la literatura de sí misma en la cual palpita "un certero instinto poético, y una pasión por la literatura" (Bioy Casares, 2008, p. 144). Cronos siempre devora a sus hijos.

En el juego de espejos se pueden identificar dos voces narrativas principales, Villafañe, autor del manuscrito esencial del relato, y Adolfo Berger Cárdenas (A.B.C), que sería un reflejo o máscara sombría de Adolfo Bioy Casares. Berger Cárdenas es el autor del "Prólogo", pero es también un personaje dentro del relato de Villafañe y el editor e intérprete del manuscrito de Villafañe. Con ello el lector entra en el ámbito de la incertidumbre y a sospechar de A.B.C. y de la supuesta imparcialidad de su testimonio. Por supuesto que A.B.C. sugiere la sucesión fundante del lenguaje escrito del abecedario occidental.

Como se verá más adelante, los personajes Carlos Oribe y Juan Luis Villafañe en ocasiones se representan uno en el otro, y también constituyen una imagen especular del mismo autor. El relato cuenta cómo ambos son creados dentro del marco de la literatura. A Villafañe lo caracteriza como "de vastas e indisciplinadas lecturas, de insaciable curiosidad intelectual"; pero también Oribe, "era intensamente literario, y quiso que su vida fuera una obra literaria. Siguió a los modelos de su predilección -Shelley, Keats- y la vida y obra conseguida no es más original que una combinación de recuerdos" (Bioy Casares, 2008, p. 147). Con ello, la narración se convierte en el símbolo del poeta, según palabras del propio autor.

El frecuente intercambio de verbos en pasado y presente contribuyen a generar esta ambigua sensación de falsedad y, a la vez la sensación de realidad. Se pueden encontrar numerosas frases cuidadosamente dispersas en el relato que subrayan este mismo efecto. Precisión de fechas en una narración imprecisa, afirmaciones explicativas que no son explicaciones. Algunos ejemplos:

hace menos de catorce que ocurrieron los hechos relatados; no alcanzado por los horrores que evoca para siempre; dos días después hicimos juntos el viaje a Bariloche; no fue indispensable que pidiera una explicación; un insospechado laberinto de persecuciones, le concedo: cuatro meses; cinco. Ni un día más (Bioy Casares, 2008, pp. 141-142)

Y la tajante afirmación, central en la imaginación narrativa: "para que en su casa no pasara el tiempo" (Bioy Casares, 2008, p. 166).

Los hechos ocurren en un momento determinado. Eso está claro. Pero el artificio de la composición hace que en la mente de los personajes se recreen como características singulares. 
Como se ha señalado, la superposición de narraciones mantiene un suspenso kafkiano que va en crescendo. Todo señala un final, pero este nunca llega. Rojas y Ovares, en su estudio sobre "El perjurio de la nieve", acertadamente proponen el siguiente esquema de los núcleos narrativos (2001, p. 125).

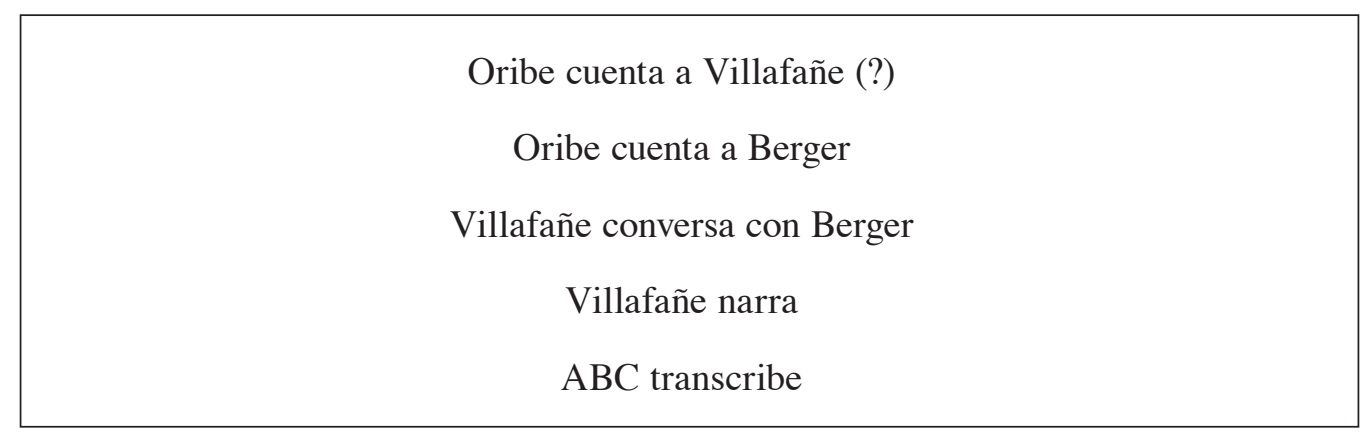

Con estos niveles expresivos se construye un ritmo cinético que contrapone y complementa la tipología de los agentes. El autor despliega con gran maestría la creación de una realidad dentro de la propia realidad convencional. Este pacto crea una ruptura y tensión con el entorno. Conflicto que, a modo de información veraz, despliega un fuerte sentimiento de intimidación e inseguridad. Es tanto asincronicidad como superposición de dos discursos narrativos, el que posee en la mente y en la experiencia vital el lector y el desplazamiento como ruptura de lo convencional. Encuentro fortuito donde irrumpe lo irracional entre las grietas de la realidad. Todo conduce hacia lo fantástico y lo ominoso; aquí la razón parece naufragar en un mar de símbolos atemporales pero ubicado en tiempos y espacios muy precisos. Hechos de naturaleza histórica que simulan ser completamente verídicos entremezclados con otros ficticios que se presentan reales. Sin embargo, el autor nos previene desde el inicio: "aventura que no es tan diáfana como aparece al primer examen" (Bioy Casares, 2008, p. 141). Por supuesto que esta ambivalencia genera la incertidumbre de lo siniestro, tal como se explicó anteriormente.

De forma que, a través de la historia referida en el manuscrito de Villafañe, prontamente surge el asunto de la cesación del tiempo; tema muy frecuente en los cuentos de hadas como el popular La bella durmiente, en Genoveva de Brabante, también en el conocido relato Rip van Wincle de W. Irving, en varios cuentos y poemas de Borges, en Las mil y una noches, etc. En todos ellos la detención del tiempo rompe con la realidad conocida. Y en varios la joven y hermosa doncella, suspendida en el tiempo, es despertada por la presencia de un intruso. En la estancia La Adela, lugar de los acontecimientos, el tiempo se ha detenido por voluntad del dueño, Vermehren, pero ahora es roto por la presencia de un infractor. El transgresor del espacio, trae con el sexo el tiempo y, con ello, apresura la caída. Pero, como en las otras narraciones tradicionales, con su presencia también llega la muerte: sexo y defunción, vida y finitud. La schopenhaueriana metafísica de la voluntad y de la representación de este mundo sufre una trágica ruptura.

La filosofía subyacente a esta narración -y quizás en toda la obra de Bioy Casares- es una especie de pandeterminismo. Más allá de Schopenhauer, citado en el relato, la voluntad de Vermehren, hacendado de origen dinamarqués, pretende detener el tiempo y asignarle un papel singular al destino tanto en el espacio de su hacienda como en la vida de sus hijas. Sin embargo, esto es otro de los juegos de ilusión. La ausencia del azar, de lo contingente e imprevisible, es sustituido por una causalidad prescrita exenta de posibilidades. Estos personajes, a modo 
de las tragedias griegas, son víctimas de un funesto destino cuya existencia forma parte de hechos relacionados directamente. Causalidad que los conduce hacia un fin trágico a la manera de Shakespeare: Oribe muere, Vermehren se suicida, y Villafañe termina carcomido por la culpa. En esta historia, la muerte de Lucía, la mujer que nace con la luz, sume al lector en las tinieblas de la imposibilidad de una simple explicación.

El encuadre en la lejana Gobernación de Chubut en la región del General Paz en la Patagonia, sirve de marco para dos localizaciones mucho más concretas: la de la Hacienda La Adela y el Hotel América. Un ambiente cambiante, una atmósfera precisa pero irreal, conducen a la sorpresa de una impensada fatalidad. Superponiendo los entornos habitados con los rurales y casi desérticos, sucesivamente va creando una atmósfera que suscita en el lector un sentimiento de irrealidad imposible de definir: la duda se convierte en sospecha, esta en incertidumbre, y al fin en desasosiego y temor. De esta forma, el espacio, cerrado y abierto, constituye no solo un encuadre supratextual, sino, esencialmente una contraposición que opone lo cercano cerrado con lo lejano abierto. Con este recurso literario se logra que el espacio, lejos de indicar una precisión narrativa, ejerza una función de indeterminación lúdica (Lotman, 2011, pp. 270-282).

Es necesario recalcar que el cronotopo de la casa cerrada es esencial en esta historia. Pero es, al mismo tiempo, el punto de contraste frente a los espacios abiertos, quizás sobrecogedores. Sirve de frontera al irremisible paso del tiempo y a una imposible suspensión vital. Es definido como un espacio de clausura con un adentro, lo interno, lo irreal, y un afuera que define lo externo, lo supuesto real. Como si de un capítulo del Libro egipcio de los muertos se tratara, la tranquera es el umbral, el puente infranqueable; límite del tiempo y del espacio: frontera de la muerte. Es el arquetipo del paso hacia un más allá incognoscible. Es el espacio de lo prohibido, del sancta sanctorum, cuya violación siempre produce funestas consecuencias. Este recinto clausurado es mancillado por la presencia inusitada del intruso. Porque lo siniestro aparece en la ruptura de los límites, de las fronteras antes cerradas entre la realidad y la ficción, entre la lógica y la sinrazón, entre lo posible y lo imposible (Reyes Velázquez, 2013, p. 18).

Sin embargo, el cuento desplaza varios personajes por otras regiones de la Argentina. Y con este desplazamiento geográfico también se produce un desplazamiento temporal. Rojas y Ovares al respecto han señalado lo siguiente:

El lector que ha cruzado el umbral del texto y ha pretendido desnudar su intimidad, tampoco puede salir de él impunemente. La imposibilidad de conocer lo realmente acontecido es el castigo que "El perjurio de la nieve" le infringe a su atrevimiento y pretensión. [...] Porque en su centro vacío el texto ha compuesto un lazo para él, en el que irremediablemente ha de caer. Es ahí donde encontrará su alteridad y también desde donde hará hablar las páginas mudas y tomará su propia voz (2001, p. 130)

Con estos mecanismos narrativos pretenden objetivar lo increíble para provocar el desconcierto. Esta aprensión no se circunscribe a la amenaza física o emocional. Al contrario, la extrañeza metafísica e intelectual, propia de la literatura fantástica, surge de la ruptura con la realidad cotidiana expresada en diversos planos narrativos. Tarde o temprano esta compleja sintaxis de relato policíaco se encamina por un sendero mucho más impalpable y complejo en el cual los nombres son presa de una contingencia inexorable. Predestinación más que accidente. En "El perjurio de la nieve" estas técnicas son como las leyes que Bioy Casares introduce -o descubre- en la propia. Es una obra policíaca, indudablemente, pero no solo eso. Es una ingeniosa narración de suspenso fantástico en la cual, a diferencia de los relatos policíacos o de novela negra, la realidad se transforma, el tiempo se detiene, los personajes se 
intercambian y se desplaza el espacio. Verdaderamente, el tiempo, el espacio y los personajes se transmutan como en un espejismo, un drama del pasado que es quizás el drama de nuestra vida.

En síntesis, en este cuento, Bioy Casares acentúa la estratificación de los ciclos en un asincronismo en el cual se superponen las diversas versiones de lo sucedido. Esta técnica de la retrospección expresiva no solo confronta los relatos, sino también los escenarios y los personajes al crear un ambiente fantasmagórico donde el tiempo y el espacio se diluyen de forma irreal. Lo siniestro bien reside en la superposición. También los personajes adquieren una sinuosa dimensión especular que, a modo de complemento, sugestionan los escenarios y los tiempos narrativos. De esta manera, el relato se vuelca sobre sí mismo recursivamente para señalar una forma poética.

\section{Contraposiciones y desdoblamientos}

El título es sugestivo en sí mismo. Bioy Casares confronta el arquetipo de la nieve, blanco, inmaculado, limpio, con la palabra "perjurio" de fuerte carga negativa. También el epígrafe es muy sugerente. La inicial referencia a Gustav Meyrink, conocido por su obra El Golem, es un recuerdo de las narraciones que este autor europeo ha escrito sobre el tema del doble. El imaginario autor de un libro inexistente es Ulrich Spiegelhater, es decir, aquel que sostiene el espejo. Bioy Casares ha utilizado el nombre de un antiguo antepasado suyo para conseguir este efecto (Iglesias y Arias, 2003). Asimismo, la propia fecha de la supuesta publicación encierra otra clave: 1919 . Al sumar los dígitos de la siguiente manera: $1+9+1+9+=20$; y luego $2+0=2$; lo cual es de nuevo un signo de la dualidad. ¿Cuál dualidad y cuál espejo, se pregunta el lector? En primer término, el de la misma narración. Imagen especular en sí misma desdoblada en varias narraciones contradictorias, pero a la vez complementarias. Y, además, enmarcado dentro de la afirmación de un recuerdo. Pero cuando el lector se ve atrapado dentro de este recuerdo la realidad se impone con más fuerza que la de un sueño.

Otro indicio importante se encuentra en una referencia posterior al escritor Jean Paul Richter. Es sabido que a este autor alemán se le debe la palabra dobles en la literatura, presente en su famosa novela Pedazos de flores, fruta y espinas; o la vida en matrimonio, la muerte y la boda del abogado Siebenkäs (1796-1797). En esta obra paradigmática el protagonista se enfrenta a su alter ego simbólicamente llamado Leibgerber, es decir, el que presta el cuerpo. Otra novela famosa es la de Dostoievski, El doble, en la cual un funcionario se encuentra con otro idéntico a él. También E. T. Hoffmann en la ya citada obra Los elíxires del Diablo, R. L. Stevenson con El extraño caso del Dr. Jekyll y Mr. Hyde, y muchos otros escritores entre los cuales se encuentran Mary Shelley, Gogol, Wilde, Mathew Lewis, Unamuno, Papini, Poe, Borges, Cortázar, Daphne du Maurier, Carlos Fuentes, Henry James, etc.. Más recientemente, en 1989, Emma Tennant transformó el conocido relato de Stevenson al incluir el protagonismo de dos mujeres en su novela, Two Women of London: The Strange case of Ms. Jekyll y Mrs Hyde (Molina Foix, 2007, pp. 9-29).

El topos del doppelgänger o de la doppelgängerinenn es muy frecuente en la literatura, podría ser la imagen de la sombra junguiana. Es decir, de la irrupción del pathos del sí mismos. El otro-sí mismo no podría ser menos que la personificación de un inconsciente insatisfecho que pugna por salir y manifestarse en toda su plenitud. Un "yo" desgarrado con un "tú" interno, imposible de objetivar. Un "yo" que es "otro" al mismo tiempo en una continua dimensión de pasado y futuro actualizados en una extraña atemporalidad. Imposibilidad de 
alcanzar un mundo comprensible que se proyecta en el doble juego de la diferencia y de la igualdad (Rodríguez, 2009). Duplicación y trasvase de existencias en imágenes especulares que concluye con una inusitada suspensión del significado. Excluido de las agendas de una sociedad fragmentada, irrumpe de nuevo para advertir y rescatar la inocencia perdida. Lo interesante para el presente estudio es que, en general, viene a comunicar información y a señalar una dirección de la vida o a exponer una nueva forma de ver la realidad. Anderson Imbert ha señalado con acierto que esta técnica implica una especie de yuxtaposición de muchos "yo" enmarcados dentro de varios "tú". Pero más allá del protagonista como deuteragonista, el desdoblamiento supone la construcción de una compleja trama (2015, pp. 63-74).

¿Qué toma Bioy Casares del tema del doble? Ya se ha mencionado que, en "El perjurio de la nieve", el autor contrapone diversos discursos y niveles de exposición. La transgresión de la realidad no consiste únicamente en la suspensión del tiempo, en la confusión de espacios o en la sugerente exposición de una presencia sobrenatural. En este marco también son frecuentes las contraposiciones de los personajes. En el relato existe una inteligente simetría que confronta las diferentes narraciones con la propuesta de identidades compensatorias que se solapan unas a otras.

Bioy Casares toma del tema del doble dos elementos esenciales. En primer término, la experiencia de la división interna del sujeto y de su reflejo. Esta imagen especular constituye una fragmentación de la realidad que se produce desde la desintegración de los sujetos. Cada personaje es uno y múltiples representaciones a la vez. En este desarrollo el juego de espejos, de sombras y de máscaras se produce en un continuo movimiento, una dinámica de la representación, que confronta el extratexto con el intertexto. Ningún personaje aparece aquí gratuitamente. En verdad, ellos configuran un complejo entramado literario, estético y existencial, en el cual se entretejen la personalidad y la obra del propio Bioy Casares (Iglesias y Arias, 2003). Ya desde el "Prólogo" y en el "manuscrito" se encuentra una delineación de los personajes principales. Este aspecto requiere mayor atención: Juan Luis Villafañe, periodista, cuenta a Carlos Oribe, el poeta. Se supone que Adolfo Berger Cárdenas es el auténtico narrador. Pero, ¿será de esta simple forma? La historia también presenta al lector otros personajes: el doctor Battis, Bella, Grungtrig. Sin faltar el hacendado de origen dinamarqués Luis Mathias Vermeheren, anteriormente mencionado, y sus cuatro hijas, Adelaida, Ruth, Margarita y, por supuesto, Lucía, la víctima. Estas mujeres son, más que personajes, una especie de taciturnas sombras nominales. Asimismo, es importante la mención de los hermanos daneses Luis y Einar, cuya anterior historia ofrece importantes pistas porque es una especie de reconstrucción previa de lo ocurrido en la estancia La Adela.

La relación de estos intérpretes -como marionetas en un teatro- son reflejo de la propia disposición anímica y artística del narrador cumpliendo con el ritual de configurar una obra en la cual cada protagonista manifiesta una dimensión a la vez singular pero compleja. En esta trama celeste cada nombre remite a una parte fractal del todo. Sin embargo, la ambivalencia de los personajes, como el tiempo y el espacio, crea la superposición de diversos planos de realidad e irrealidad para configurar un relato indeterminado. Es interesante la forma como lo analizan Rojas y Ovares:

\footnotetext{
Se impone pues, la relación de los personajes principales como dobles: Villafañe y Oribe, que aparecen como asesino y detective en la Relación; ABC y Villafañe, que son los autores de sus textos respectivos; al mismo tiempo, ambos son amigos de Oribe y críticos de la obra de este último y ABC crítico de la obra de Villafañe. También, comparten funciones de detectives: Villafañe con respecto a Oribe y ABC como lector del texto de Villafañe. Berger Cárdenas
} 
es el doble de ABC y éste, por las iniciales, lo es de Adolfo Bioy Casares. A su vez, los hermanos daneses Luis y Einar se intercambian el papel de agitadores y traidores en cierta revuelta religiosa, ocurrida en Dinamarca antes del viaje de Luis a la Argentina (2001, p. 122)

Por ese motivo la identificación del lector con una sola voz es imposible. Son representaciones icónicas y miméticas. Pues no parece tener una lógica continua ya que se produce una permanente relación de correspondiente similitud entre las emociones del lector y de los frecuentes traslapes de los personajes. En consecuencia, se desencadena una especie de trauma cuyo resultado es la sensación de irrealidad y desconcierto. Al respecto se puede suscribir la opinión de Marcelo Pichón Riviére, "Aún en los relatos fantásticos encontramos personajes en cuya realidad irresistiblemente creemos; nos atrae en ellos, como en la gente de carne y hueso, una sutil amalgama de elementos conocidos y misteriosos del destino" (1991, p. 123).

Pero hay algo mucho más sutil y muchísimo más amenazador. Un segundo elemento difuso que también se ha tomado del doble, que está presente en todo el desarrollo del cuento y le otorga su identidad particular como una textura literaria que se impone a la manera de una tenue pero persistente tiniebla. Basado en la inevitable ruptura que existe en todo acto comunicativo el autor construye un relato en donde la comunicación impide cualquier cierre y acusa la imposibilidad de límites expresivos absolutos. Ciertamente, lleva al extremo la fractura implícita en todo evento de comunicación y, a la vez, la ilusión de acceder unilateralmente a un mundo en sí mismo fragmentado. La duplicidad es división, ruptura, pero también una necesaria complementación. Es diferencia e igualdad simultáneamente, las cuales, si se suman, en conjunto implican una radical apertura y un rechazo de cualquier intento de cierre del discurso. Este efecto metaliterario conlleva la imposibilidad de establecer una metafísica rígida y lineal. Y, por supuesto, la consecuencia epistemológica de la invalidez de un discurso ingenuo donde se enfrenta el sujeto y el objeto. Más bien, el sujeto y el objeto se involucran en el acto discursivo de la narración hasta romper los límites del significado. En otras palabras, Bioy Casares en este relato muestra cómo la realidad y el significado despliegan una gama de posibilidades inherentes e inaprensibles. Es una especie de relatividad e indeterminación ontológica que constituye un todo dinámico en continuo movimiento, donde están implicados tanto el autor como el lector en las diferentes representaciones de los personajes y en los diversos estratos narrativos.

En consecuencia, las identidades simétricas y los niveles discursivos hacen que el espectro de lo fantástico se convierta en una especie de ciudad circular de tipo borgiano. Esta organización sintagmática es un sistema de codificación de signos que reordenan los valores del mundo creando una metaliteratura de lo especular. Es imposible comprender lo incomprensible porque desde la primera secuencia narrativa hasta la última el universo de Bioy Casares reclama la apertura y la redefinición funcional de la lectura desde un código cuidadosamente estructurado que construye una poética del texto fantástico. Este cosmos trasciende las leyes de la clasificación para eludir los códigos del mundo extraliterario del núcleo realista. La percepción ambigua de los sucesos y de la continua superposición de los personajes sobrepasa la comprensión lógica y se hace imposible descifrar el mundo objetivo explicado mediante la razón. El desdoblamiento de los sujetos no permite un discurso isotópico, es decir, congruente y homogéneo, expuesto de acuerdo con las leyes del mundo racional. Es, más bien, una estructura narrativa que remite a lo heterogéneo e inverosímil propio del acto narrativo como imposibilidad de una absoluta comunicación. Es, por supuesto, la irrupción de lo fantástico. 
Como ha señalado Gisela Schmidt, las yuxtaposiciones iconológicas constituyen un proceso transferencial del sujeto; imagen del espejo que se desenvuelve en una estética de la hermenéutica de la participación (2001, pp. 49-69). Evidentemente, la transgresión de los marcos narrativos es intencional y con ello se logra aumentar la sensación de desconcierto y de estupor. Inversiones e imágenes que se presentan en planos concomitantes: los personajes, la historia contada y el propio relato. Pero, además, nunca son estáticos: es un continuo dinamismo donde cada inversión adquiere un reflejo en el otro nivel. Con ello se crea una ilusoria sensación de avance, de progreso, cuando en realidad, lo estático es un factor esencial en el relato.

\section{Reflexiones finales}

La acertada expresión de Bioy Casares, "la tenaz memoria de estos hechos", remite, en realidad, a una desmemoria; un complejo entramado de olvidos, recuerdos e inversiones narrativas. Supone descifrar un código oculto con el cual el lector podría seguir el hilo del enigma. Sin embargo, no se deja aprehender pues constituye una realidad dentro de realidades; algo así como el misterio oculto en las diferentes muñecas dentro de una muñeca rusa o de una singular figura fractal. El todo y la parte son los mismos, pero a la vez diferentes, pues ocupan espacios indeterminados en la consciencia del lector, no obstante incomparables. En este itinerario de la existencia el sendero lo marca lo irresuelto. Tan solo un sueño o un exiguo silencio. "El perjurio de la nieve" es un excelente ejemplo de esta ambigua e imprecisa realidad en la cual el valor no reside en lo inusitado del final sino en la ausencia de final. ¿No será que recuerda la vida misma, quizás la propia?

En efecto, la contextura de la narrativa fantástica supone un diseño o configuración particular, a saber: la ruptura de los límites de la realidad, de la construcción de mundos extraordinarios pero cercanos al de nuestra cotidianidad. El suspenso, producto de la contraposición o transgresión de la realidad cotidiana, de la superposición de personajes, de la ruptura epistemológica del acto comunicativo conlleva un resquebrajamiento de los límites de la racionalidad. Esta vacilación e indeterminación rompe las leyes de lo acostumbrado. La existencia de inéditos códigos funda un mundo discordante. Bioy Casares asume esta condición de transgresión como una totalidad metafísica. No es la ruptura dentro de una delimitada parcialización política, sentimental, familiar o de ningún otro tipo particular; más bien es la creación de rupturas totales frente a un mundo convencionalmente establecido como real.

Las leyes de este universo narrativo son un cosmos construido con datos del caos. Como señalara el propio autor en su propuesta sobre las leyes del cuento fantástico y policíaco, no se restringe a un único código o a un único conjunto de leyes. Cada narración tiene sus propias normas, ya sean generales o especiales, el escritor resuelve su enigma dentro del mundo que habita. Pero siempre, e inevitablemente, superponiendo dos realidades, la intratextual y la extratextual en un complejo juego de espejos y de duplicidades. En este cuento, como en toda la literatura fantástica, no solo existe una aristotélica función catártica y de compensación cultural y subliminal, propuesta por Freud, sino también de cuestionamiento de las unidades de tiempo, espacio y personaje que le permite destruir los mitos dominantes en la sociedad. Como se señaló al principio, este tipo de literatura muestra la vulnerabilidad y las rupturas de la ideología dominante y desnuda el caos oculto en una falsa realidad autoritaria y despótica. Lo fantástico es una literatura de la subversión. En ella, no solo la 
realidad externa, sino el propio yo adquieren un carácter mucho más endeble, complejo y aún vulnerable: un "yo" que es muchos "tú".

Los recursos utilizados por Bioy Casares, en particular la sobreexposición de narraciones creíbles pero discordantes, la elusiva presencia del tiempo y del espacio, así como los elementos propios del topos literario del doppelgänger, tales como el desdoblamiento y complementación de los personajes, la presencia de las imágenes especulares, la ruptura del acto comunicativo en una epistemología radicalizada, consiguen construir un universo paralelo con leyes propias y con códigos estéticos funcionales. En este caso el desconcierto y la perplejidad provienen de varias explicaciones razonables, pero contradictorias, sobre un acontecimiento que es en sí mismo cotidiano; la muerte de una muchacha no ocasionaría más temor que el propio del crimen pasional. Sin embargo, el relato confronta al lector con una ruptura de la lógica de la realidad para ser sustituida por otra ilusoria y a la vez creíble. Porque, si no fuera verosímil, no produciría el efecto de sorpresa y turbación propia de lo siniestro.

Este revés de la trama que presenta Bioy Casares ¿no es acaso la peculiar reconstrucción de una realidad que se niega a ser reducida a lo conocido y familiar? Una ruptura que fragmenta la tradicional estructura de lo habitual y cotidiano e infringe sus leyes. Por supuesto, la imagen de lo siniestro es frecuente en la literatura. Tanto Borges como Cortázar construyen mundos insólitos a partir de objetos cotidianos: un espejo, una enciclopedia, una brújula, un libro, una escalera, un par de zapatos... Porque el sentido de lo ominoso no es sino la medida de la propia debilidad. De la incapacidad para reconocer un más allá, que no es, en paradoja siniestra, sino el más cercano más acá.

En conclusión, se puede afirmar que esta literatura dentro de la literatura es una poética de la ruptura de la lógica donde la invención adquiere la naturaleza de una superposición racional. Con ello el autor concibe una epistemología del compromiso del lector. Si bien el lector nunca ha sido pasivo, en la literatura fantástica en general y en esta narración en particular, el lector es un personaje esencial de la trama (Warning, 1989, pp. 30-32).

Tal y como se señaló al principio de este trabajo, la fragmentación complementaria de los personajes y la sutil descomposición del acto narrativo en una epistemología que pretende superar la dualidad sujeto-objeto no solo exponen la trama del relato sino, constituyen una propuesta sobre la metaliteratura. Una forma de ver y de pensar un mundo fantástico más allá de las leyes del universo extraliterario, pero, a la vez extrapolado con la lógica cotidiana. Una realidad visible se transmuta en ilusión; alquimia que nos introduce en extrañas dimensiones del universo.

"El perjurio de la nieve" de Bioy Casares es el falso testimonio del narrador, por supuesto. En él se oculta la pertinaz falsedad de la realidad. Porque, como es sabido, en la dimensión de la poética -como en la vida misma- las apariencias engañan.

\section{Bibliografía}

Anderson Imbert, E. (2015). Teoría y técnica del cuento. Barcelona: Ariel.

Bioy Casares, A. (2008). La trama celeste. Madrid: Alianza Editorial.

Bioy Casares, A. (1997). Prólogo. En J. L. Borges, S. Ocampo y A. Bioy Casares. Antología de la literatura fantástica. (pp. 5-12). Barcelona: EDHASA. 
Borges, J. L. (2007). Prólogo a La invención de Morel de Adolfo Bioy Casares. En J. L. Borges. Obras Completas. Tomo IV. (pp. 29-31). Buenos Aires: Emecé.

Bravo, V. A. (1988). La transgresión del límite y la producción de lo fantástico. En V. A. Bravo (Ed.). La irrupción y el límite. Hacia una reflexión sobre la narrativa fantástica y la naturaleza de la ficción. (pp. 29-62). México: UNAM.

Eagleton, T. (2013). El acontecimiento de la literatura. Barcelona: Península.

Freud, S. (1981). Lo siniestro. Obras completas. Tomo III. (pp. 2483-2505). Madrid: Biblioteca Nueva.

García Berrio, A. (1994). Teoría de la literatura. (La construcción del significado poético). Madrid: Ediciones Cátedra, S. A.

Genette, G. (1998). Nuevo discurso del relato. Madrid: Cátedra, S. A.

Hawking, S. (2011). Los sueños de los que está hecha la materia. Los textos fundamentales de la física cuántica y cómo revolucionaron la ciencia. Barcelona: Crítica, S .L.

Iglesias, J. y Arias, S. R. (2003). Los Bioy. Barcelona: Tusquets Editores, S. A.

Jackson, R. (2001). Lo “oculto” de la cultura. En D. Roas (Comp.). Teorías de lo fantástico. (pp. 141-152). Madrid: Arco Libros, S. A.

Lem, S. (1974). Todorov's Fantastic Theory of Literature. Science Fiction Studies, 1 (4), $227-$ 237. Recuperado de http://www.depauw.edu/sfs/backissues/4/lem4art.htm

Lotman, Y. M. (2011). Estructura del texto artístico. Madrid: Akal, S. A.

Martínez Fernández, J. E. (2001). La intertextualidad literaria. Madrid: Cátedra.

Molina Foix, J. A. (Ed.). (2007). Álter ego. Cuento de dobles (una antología). Madrid: Siruela, S. A.

Moretti, F. (1996). Modern Epic. The Worl-System from Goethe to García Márquez. LondonNew York: Verso.

Nandorfy, M. J. (2001). La literatura fantástica y la representación de la realidad. En D. Roas (Comp.). Teorías de lo fantástico. (pp. 243-261). Madrid: Arco Libros, S. A.

Pichón Riviére, M. (1991). Introducción y notas. En A. Bioy Casares. La invención y la trama (I). Barcelona: RBA Editores, S. A.

Reyes Velázquez, A. (2013). La casa bioycasareana y el mito en "El perjurio de la nieve". Recuperado de http://www.uba.ar/aihbuenosaires2013/actas/seccion6/La\%20casa\%20 bioycasareana $\% 20 \mathrm{y} \% 20 \mathrm{el} \% 20$ mito

Roas, D. (2011). Tras los límites de lo real. Una definición de lo fantástico. Málaga: Páginas de espuma.

Rodríguez Zamora, J. M. (2009). El Héroe. Literatura y psicología analítica. Revista de Filología y Lingüística, 35 (1), 65-86.

Rojas, M. y Ovares, F. (2001). La tenaz memoria de los hechos. "El perjurio de la Nieve" de Adolfo Bioy casares. Revista Iberoamericana, 67 (194-195), 121-133.

Ruiz-Lapuente, P. (2011). El enigma de la realidad. Barcelona: Gedisa. 
Schmidt, G. (2001). Mirror Image and Therapy. Berna: Peter Lang AG, European Academic Publisher.

Schopenhauer, A. (2004). El mundo como voluntad y representación. Madrid: Trotta. Todorov, T. (2006). Introducción a la literatura fantástica. Buenos Aires: Paidós.

Warning, R. (Ed.). (1989). Estética de la recepción. Madrid: Visor, S. A. 